\title{
How do soluble oligomers of amyloid $\beta$-protein impair hippocampal synaptic plasticity?
}

\author{
Shaomin Li, Ganesh M. Shankar and Dennis J. Selkoe* \\ Center for Neurologic Diseases, Brigham and Women's Hospital, Harvard Medical School, Boston, MA, USA \\ ${ }^{*}$ Correspondence: dselkoe@rics.bwh.harvard.edu
}

\section{A commentary on}

Soluble oligomers of amyloid $\beta$-protein facilitate hippocampal long-term depression by disrupting neuronal glutamate uptake

by Li, S., Hong, S., Shepardson, N.E., Walsh, D.M., Shankar, G.M., Selkoe, D. Neuron 2009; 62, 788-801.

Alzheimer's disease (AD), the most common neurodegenerative disorder, is characterized by progressive memory and cognitive impairment and the cerebral accumulation of extracellular amyloid plaques and intraneuronal neurofibrillary tangles. A principal neuropathological finding in $\mathrm{AD}$ subjects is cortical atrophy associated with degeneration of neurites, decreased dendritic spine density and frank neuronal loss (Terry et al., 1991; Knobloch and Mansuy, 2008). Although the specific molecular initiators of the $\mathrm{AD}$ process remain unknown in most patients, biochemical studies indicate that the severity of cognitive impairment in $\mathrm{AD}$ correlates more strongly with the cortical levels of soluble amyloid $\beta$-protein $(\mathrm{A} \beta$ assemblies than with the burden of insoluble amyloid plaques (Lue et al., 1999; McLean et al., 1999; Shankar et al., 2008). Extensive experimental work on hippocampal plasticity has indicated that the induction of longterm synaptic depression (LTD) results in decreased dendritic spine volume or outright elimination of spines (Matsuzaki et al., 2004; Nägerl et al., 2004; Zhou et al., 2004), changes which may parallel molecular and structural aspects of synaptic failure in $\mathrm{AD}$. Therefore, understanding how $A \beta$ impairs hippocampal synaptic function at the molecular level could enable the development of specific neuroprotective therapies for $\mathrm{AD}$.

Studies from numerous laboratories have now established that soluble $A \beta$ oligomers can inhibit long-term potentiation (LTP), or the strengthening of synapses, in the hippocampus. But heretofore, only a few studies have examined the effects of $A \beta$ on the induction of LTD, and those few have yielded inconsistent results. For example, synthetic $A \beta$ peptides were reported to potently enable the induction of LTD in CA1 in an NMDARdependent manner in vivo (Kim et al., 2001; Cheng et al., 2009), whereas other studies found no effect on LTD in slices (Wang et al., 2002, 2004; Raymond et al., 2003). To address this problem, we recently extracted buffersoluble $A \beta$ oligomers directly from the brains of typical $\mathrm{AD}$ patients and demonstrated that these species can facilitate LTD induction in hippocampal slices of wild-type mice (Shankar et al., 2008). While the induction of both LTP and LTD requires glutamatergic transmission, the direction in which synaptic strength is modulated by the specific class of glutamate receptor that is activated, the kinetics of cytosolic calcium concentration, and the initiation of intracellular signaling cascades. Specifically, we found that LTD induction was facilitated by pathophysiologically relevant low concentrations of soluble $\mathrm{A} \beta$ oligomers through activation of either NMDA receptors or metabotropic glutamate receptors (mGluRs), depending on the electrical stimulation protocol used to induce the LTD (Li et al., 2009). Given that several prior studies, including our own, have already shown that $A \beta$ has little or no effect on presynaptic neurotransmitter release probability (e.g., Townsend et al., 2006; Shankar et al., 2008; Cheng et al., 2009), we hypothesized that the $A \beta$ oligomers alter synaptic glutamate concentration by disrupting glutamate transport mechanisms. In the current study, we report that pharmacologically blocking glutamate uptake closely recapitulates the effects of $A \beta$ on LTD induction, suggesting that $A \beta$ oligomers bias towards synapse weakening in part through such a mechanism (Li et al., 2009).

A growing number of reports indicate that glutamate transporters are disturbed in AD (Masliah et al., 1996). The levels of transporters such as GLAST/EAAT1 and GLT-1/EAAT2 are reduced in postmortem AD brain tissue and in APP transgenic mice (Maragakis et al., 2004; Jacob et al., 2007). Synthetic A $\beta$ (at supraphysiological concentrations) has been shown to inhibit glutamate uptake in cultured neurons and astrocytes (Harris et al., 1996; Harkany et al., 2000; Fernández-Tomé et al., 2004) and in oocytes (Gu et al., 2004). Although most glutamate transporters are located on astrocytes, reduced neuronal expression of EAAT1 was also suggested to be an early marker of neuronal dysfunction in $\mathrm{AD}$, preceding or occurring on a similar timeline to the expression of hyper-phosphorylated tau protein in the same neurons of AD brains (Scott et al., 2002). Interestingly, it was demonstrated recently that detergent insoluble EAAC1/EAAT3 transporters accumulate aberrantly in hippocampus in $\mathrm{AD}$ subjects (Duerson et al., 2009). Taken together, these various reports suggest that neuronal and/or glial glutamate uptake may be interrupted in $\mathrm{AD}$.

Glutamate transporters play the important role of regulating concentrations of glutamate in the extracellular space, keeping it at low levels. Without normal activity of glutamate transporters, glutamate would accumulate to cytotoxic levels and could contribute to progressive neuronal loss in AD (Pomara et al., 1992; Harkany et al., 2000). Early AD studies focused on frank $A \beta$-enhanced excitotoxicity mediated through glutamate receptors, especially NMDA receptors (Greenamyre and Young, 1989; Mattson et al., 1992; Hynd et al., 2004). However, the perturbations in extracellular glutamate levels resulting from altered transport kinetics could even be responsible for the more subtle ultrastructural alterations noted in $\mathrm{AD}$, such as dendritic spine loss. In vivo microdialysis recently revealed that soluble $A \beta$ oligomers secreted by APP-transfected cells, when microinjected into wild-type rat brain, can 
significantly increase the hippocampal levels of extracellular glutamate but not GABA or aspartate (O'Shea et al., 2008). Inhibition of glutamate uptake by the pharmacological agent TBOA has been shown to increase spontaneous epileptiform discharges, and this increased excitability can be blocked by the NMDA antagonist, AP5 (Campbell and Hablitz, 2004). In our current study, we found that the effects of $A \beta$ oligomers in facilitating LTD in hippocampal slices were very similar to those of TBOA (Li et al., 2009). Interestingly, $A \beta$ accumulation in vivo has been found to significantly increase spontaneous nonconvulsive seizure activity in cortical and hippocampal networks in APP transgenic mice (Palop et al., 2007). In the context of these various studies, our new findings that soluble $\mathrm{A} \beta$ oligomers can facilitate the induction of LTD through both an mGluR pathway (300pulse stimulation protocol) and a NMDAR pathway (900-pulse stimulation protocol) and that this LTD induction is mimicked by the effect of TBOA suggest that a common upstream element, the neuronal glutamate transporter, is misregulated by diffusible $A \beta$ oligomers.

\section{REFERENCES}

Campbell, S. L., and Hablitz, J. J. (2004). Glutamate transporters regulate excitability in local networks in rat neocortex. Neuroscience 127, 625-635.

Cheng, L., Yin, W. J., Zhang, J. F., and Qi, J. S. (2009). Amyloid beta-protein fragments 25-35 and 31-35 potentiate long-term depression in hippocampal CA1 region of rats in vivo. Synapse 63, 206-214.

Duerson, K., Woltjer, R. L., Mookherjee, P., Leverenz, J. B., Montine, T. J., Bird, T. D., Pow, D. V., Rauen, T., and Cook, D. G. (2009). Detergent-insoluble EAAC1/ EAAT3 aberrantly accumulates in hippocampal neurons of Alzheimer's disease patients. Brain Pathol. 19, 267-278.

Fernández-Tomé, P., Brera, B., Arévalo, M. A., and de Ceballos, M. L. (2004). Beta-amyloid 25-35 inhibits glutamate uptake in cultured neurons and astrocytes: modulation of uptake as a survival mechanism. Neurobiol. Dis. 15, 580-589.

Greenamyre, J. T., and Young, A. B. (1989). Excitatory amino acids and Alzheimer's disease. Neurobiol. Aging 10, 593-602.

Gu, Q. B., Zhao, J. X., Fei, J., and Schwarz, W. (2004). Modulation of $\mathrm{Na}(+), \mathrm{K}(+)$ pumping and neurotransmitter uptake by beta-amyloid. Neuroscience 126, 61-67.

Harkany, T., Abrahám, I., Timmerman, W., Laskay, G., Tóth, B., Sasvári, M., Kónya, C., Sebens, J. B., Korf, J., Nyakas, C., Zarandi, M., Soos, K., Penke, B., and Luiten, P. G. (2000). beta-amyloid neurotoxicity is mediated by a glutamate-triggered excitotoxic cascade in rat nucleus basalis. Eur. J. Neurosci. 12, 2735-2745.

Harris, M. E., Wang, Y., Pedigo, N. W. Jr., Hensley, K., Butterfield, D. A., and Carney, J. M. (1996). Amyloid beta peptide (25-35) inhibits $\mathrm{Na}$--dependent glutamate uptake in rat hippocampal astrocyte cultures. J. Neurochem. 67, 277-286.

Hynd,M.R., Scott,H.L., and Dodd,P.R. (2004). Glutamatemediated excitotoxicity and neurodegeneration in Alzheimer's disease. Neurochem. Int. 45, 583-595.

Jacob, C. P., Koutsilieri, E., Bartl, J., Neuen-Jacob, E., Arzberger, T., Zander, N., Ravid, R., Roggendorf, W., Riederer, P., and Grünblatt, E. (2007). Alterations in expression of glutamatergic transporters and receptors in sporadic Alzheimer's disease. J. Alzheimers Dis. 11, 97-116.

Kim, J. H., Anwyl, R., Suh, Y. H., Djamgoz, M. B., and Rowan, M. J. (2001). Use-dependent effects of amyloidogenic fragments of (beta)-amyloid precursor protein on synaptic plasticity in rat hippocampus in vivo. J. Neurosci. 21, 1327-1333.

Knobloch, M., and Mansuy, I. M. (2008). Dendritic spine loss and synaptic alterations in Alzheimer's disease. Mol. Neurobiol. 37, 73-82.

Li, S., Hong, S., Shepardson, N. E., Walsh, D. M., Shankar G. M., and Selkoe, D. (2009). Soluble oligomers of amyloid beta protein facilitate hippocampal longterm depression by disrupting neuronal glutamate uptake. Neuron 62, 788-801.

Lue, L. F., Kuo, Y. M., Roher, A. E., Brachova, L., Shen, Y., Sue, L., Beach, T., Kurth, J. H., Rydel, R. E., and Rogers, J. (1999). Soluble amyloid beta peptide concentration as a predictor of synaptic change in Alzheimer's disease. Am. J. Pathol. 155, 853-862.

Maragakis, N. J., Dykes-Hoberg, M., and Rothstein, J. D. (2004). Altered expression of the glutamate transporter EAAT2b in neurological disease. Ann. Neurol. 55, 469-477.

Masliah, E., Alford, M., DeTeresa, R., Mallory, M., and Hansen, L. (1996). Deficient glutamate transport is associated with neurodegeneration in Alzheimer's disease. Ann. Neurol. 40, 759-766.

Matsuzaki, M., Honkura, N., Ellis-Davies, G. C., and Kasai, H. (2004). Structural basis of long-term potentiation in single dendritic spines. Nature 429, 761-766.

Mattson, M. P., Cheng, B., Davis, D., Bryant, K., Lieberburg, I., and Rydel, R. E. (1992). Beta-amyloid peptides destabilize calcium homeostasis and render human cortical neurons vulnerable to excitotoxicity. J. Neurosci. 12, 376-389.

McLean, C. A., Cherny, R. A., Fraser, F. W., Fuller, S. J., Smith, M. J., Beyreuther, K., Bush, A. I., and Masters, C. L. (1999). Soluble pool of Abeta amyloid as a determinant of severity of neurodegeneration in Alzheimer's disease. Ann. Neurol. 46, 860-866.

Nägerl, U. V., Eberhorn, N., Cambridge, S. B., and Bonhoeffer, T. (2004). Bidirectional activitydependent morphological plasticity in hippocampal neurons. Neuron 44, 759-767.

O'Shea, S. D., Smith, I. M., McCabe, O. M., Cronin, M. M., Walsh, D. M., and O'Connor, W. T. (2008) Intracerebroventricular administration of amyloid b-protein oligomers selectively increases dorsal hippocampal dialysate glutamate levels in the awake rat. Sensors 8, 7428-7437.
Palop, J. J., Chin, J., Roberson, E. D., Wang, J., Thwin, M. T., Bien-Ly, N., Yoo, J., Ho, K. O., Yu, G. Q., Kreitzer, A., Finkbeiner, S., Noebels, J. L., and Mucke, L. (2007). Aberrant excitatory neuronal activity and compensatory remodeling of inhibitory hippocampal circuits in mouse models of Alzheimer's disease. Neuron 55, 697-711.

Pomara, N., Singh, R., Deptula, D., Chou, J. C., Schwartz, M. B., and LeWitt, P. A. (1992). Glutamate and other CSF amino acids in Alzheimer's disease. Am. J. Psychiatry 149, 251-254.

Raymond, C. R., Ireland, D. R., and Abraham, W. C. (2003). NMDA receptor regulation by amyloid-beta does not account for its inhibition of LTP in rat hippocampus. Brain Res. 968, 263-272.

Scott, H. L., Pow, D. V., Tannenberg, A. E., and Dodd, P. R. (2002). Aberrant expression of the glutamate transporter excitatory amino acid transporter 1 (EAAT1) in Alzheimer's disease. J. Neurosci. 22, RC206.

Shankar, G. M., Li, S., Mehta, T. H., Garcia-Munoz, A., Shepardson, N., Smith, I., Brett, F. M., Farrell, M. A., Rowan, M. J., Lemere, C. A., Regan, C. M., Walsh, D. M., Sabatini, B. L., and Selkoe, D. J. (2008). Soluble amyloid $\beta$-protein dimers isolated directly from Alzheimer disease patients potently impair synaptic plasticity and memory. Nat. Med. 14, 837-842.

Terry, R. D., Masliah, E., Salmon, D. P., Butters, N., DeTeresa, R., Hill, R., Hansen, L. A., and Katzman, R. (1991). Physical basis of cognitive alterations in Alzheimer's disease: synapse loss is the major correlate of cognitive impairment. Ann. Neurol. 30, 572-580.

Townsend, M., Shankar, G. M., Mehta, T., Walsh, D. M., and Selkoe, D. J. (2006). Effects of secreted oligomers of amyloid beta-protein on hippocampal synaptic plasticity: a potent role for trimers. J. Physiol. (Lond.) 572, 477-492.

Wang, H. W., Pasternak, J. F., Kuo, H., Ristic, H., Lambert, M. P., Chromy, B., Viola, K. L., Klein, W. L., Stine, W. B., Krafft, G. A., and Trommer, B. L. (2002). Soluble oligomers of beta amyloid (1-42) inhibit long-term potentiation but not long-term depression in rat dentate gyrus. Brain Res. 924, 133-140.

Wang, Q., Rowan, M. J., and Anwyl, R. (2004). Betaamyloid-mediated inhibition of NMDA receptordependent long-term potentiation induction involves activation of microglia and stimulation of inducible nitric oxide synthase and superoxide. J. Neurosci. 24, 6049-6056.

Zhou, Q., Homma, K. J., and Poo, M. M. (2004). Shrinkage of dendritic spines associated with longterm depression of hippocampal synapses. Neuron 44, 749-757.

Received: 02 December 2009; accepted: 26 February 2010; published online: 19 March 2010.

Citation: Li S, Shankar GM and Selkoe DJ (2010) How do soluble oligomers of amyloid $\beta$-protein impair hippocampal synaptic plasticity? Front. Cell. Neurosci. 4:5. doi: 10.3389/fncel.2010.00005

Copyright (c) $2010 \mathrm{Li}$, Shankar and Selkoe. This is an open-access article subject to an exclusive license agreement between the authors and the Frontiers Research Foundation, which permits unrestricted use, distribution, and reproduction in any medium, provided the original authors and source are credited. 